\title{
Quarantine: Voluntary or Not?
}

\author{
Lawrence O. Gostin, Steven D. Gravely, Steve Shakman, \\ Howard Markel, and Marty Cetron (Moderator)
}

\section{Marty Cetron}

By utilizing quarantine and isolation as public health tools we are in many ways battling twenty-first century pathogens with a fourteenth century toolbox. It is important for all to recognize the technical difference between the distinct public health measures of isolation and quarantine. Isolation is the separation and/or restricted movement of persons with a contagious disease from the larger population. Quarantine is a separation and restriction placed on the movement of persons presumed to have been exposed to a contagious disease or suspected to be a carrier of a contagious disease. Although these are distinct health measures, they are often both addressed through the state quarantine laws. From a modern public health perspective, the best way to implement isolation and quarantine is through voluntary means, although in some cases compulsory means may be required.

Ideally, isolation and quarantine are most effective through the early detection of contagious disease cases and identification of possible carriers.

Isolation enables the authorities the ability to conduct contact tracing from infected individuals and may result in the home quarantine of these exposed contacts. Contact tracing is a resource-intensive undertaking and this reality was underscored by the global experience with SARS in 2003. Out of necessity, public health agencies generally relied on home quarantine for the close contacts of SARS patients and only utilized institutionalized quarantine for selected populations at risk who did not have suitable home environments in the vicinity. Work quarantines were occasionally applied to health care workers. Quarantine measures effectively enable health authorities to remove affected persons from subsequent chains of transmission.

In the twenty-first century, isolation and quarantine actions taken by public health officers are a delicate balance between the public good and individual liberties. Generally, the states are responsible for the regulation and enforcement of public health controls within their own borders. Throughout the fifty states, there is a significant variation of quarantine and isolation laws and many of them predate the advent of modern epidemiology principles. The powers held by the federal government to implement isolation and quarantine are limited primarily to the control of eight communicable diseases enumerated in federal executive orders and apply to international arrivals and persons engaging in interstate movement. In addition to these circumstances, the U.S. Department of Health and Human Services can intervene within states to enact isolation and quarantine if the state requests such intervention or if it recognizes a state has failed in its containment efforts. In issues where a specified communicable disease may affect interstate commerce, the federal government also retains the power to assert its authority by directing control measures. Controlling the movement of conveyances either at ports of international arrival or interstate is more broadly authorized than restricting the movement of individuals which is restricted to the eight diseases specified by Executive Order.

In the recent SARS outbreak, public health officers in Toronto utilized voluntary quarantine and isolation measures to control its spread. The populace of over 27,000 affected persons was overwhelmingly cooperative with these requests. Based on this experience, it is not accurate to simply assert "the public will not accept quarantine measures," as some critics suggest. 
Effective communication is critical for gaining public trust and participation in community containment measures. Reframing the stigmatizing term "quarantine" along the lines of a "snow day" or "shelter in place" principles may aid in acceptance. A snow day is simply a request to limit interpersonal contacts and slow social interaction during a public health emergency by asking citizens to stay home for a specified period of time. Such voluntary measures are less threatening, leverage people's instinct for self preservation (as opposed to fleeing) and may require fewer resources than an enforced compulsory quarantine. Snow day recommendations can be implemented almost instantaneously and can be quickly leveraged through the media. For the concept of voluntary quarantine to work most effectively in the highly individualized United States, it must be integrated into the broad understanding of our society as a tool for ensuring public safety and be implemented according to strict ethical principles.

\section{Lawrence O. Gostin}

It is my contention that isolation and quarantine are both the simplest and most complex problems in public health practice. This interesting dichotomy is examined in a piece on the International Health Regulations that recently appeared in the Jourmal of the American Medical Association L.O. Gostin, "International Infectious Disease Law: Revision of the World Health Organization's International Health Regulations," 291 JAMA 2623 (2004).

In terms of simplicity, isolation and quarantine, as we understand them today, rest on three well-understood bedrock principles: clear substantive standards for imposition, and the presence of procedural safeguards under the due process and equal protection clauses of the 14th Amendment. Despite these wellrecognized principles, isolation and quarantine have proven to be extremely complex public health measures to implement.

In taking a "new look at an old tool," a number of legal scholars and ethicists have grappled with how to reconcile the complex legal and scientific issues of quarantine and isolation with its effective application. Through academic publications, dialogue, and the recent SARS experience, we have identified seven ethical principles that must be considered in regards to quarantine: the precautionary principle, use of the least restrictive alternative, a transparent public health system, a sense of fairness, just compensation for those impacted, keeping those subjected to isola- tion and quarantine in a humane environment, and abiding by the rule of law. See L.O. Gostin, et al., "Ethical and Legal Challenges Posed by Severe Acute Respiratory Syndrome: Implications for the Control of Severe Infectious Disease Threats," 290 JAMA 3229 (2003). The recent SARS epidemic is highly instructive to the future implementation of isolation and quarantine measures. In some ways this public health crisis was a throwback to the "pre-therapeutic" era, as it signaled the first large-scale use of quarantine in North America in several decades.

Despite the identification of important legal and ethical considerations, there exists a difficult public health paradox between the choice of early and delayed action concerning quarantine. Early action to quench an epidemic can be a silent victory if effective, but early action where no anticipated epidemic takes place can open public health authorities to criticisms of being "heavy-handed" and "jumping the gun." The best antidote to this dilemma remains the existence of a transparent, fair and humane system of initiating and enforcing quarantine and isolation measures when necessary.

\section{Steven D. Gravely}

My experience focuses on the process by which appropriate public policy becomes law. The specifics of what occurred in Virginia during the revision of our communicable disease laws may not be completely relevant to all jurisdictions, but the process in which these changes were made is relevant to others.

Bioterrorism and SARS spurred a critical reevaluation of public health strategies and tools for containing communicable diseases. The continuum of these response strategies exists within a legal framework of law and regulation. Nationwide, many of these laws are antiquated and insufficient to react to a communicable disease outbreak considering modern notions of science, due process, and equal protection.

In Virginia, the state faced an interesting dilemma because the state quarantine statute was only one sentence. The isolation statute was of extremely limited applicability because it only explicitly mentioned tuberculosis and HIV. It also contained extensive "front end" due process provisions that required the identification of "at risk" behavior and counseling prior to the ordering of isolation. There was a consensus that the existing isolation statute would not work in a "SARS-type" event or other "wildfire scenario" involving rapidly spreading communicable disease. As a result of inadequate communicable disease 
laws, we set out to revise them to appropriately deal with "wildfire" scenarios.

Our endeavor started with a comprehensive review of all Virginia laws for responding to communicable disease threats. This survey was not limited to public health laws. A central aim of our working group was the creation of a "scalable" response capability depending upon both the extent and nature of a disease threat. An additional goal was to clarify the role of the judiciary in a public health response and require the adoption of rules to prepare the courts in the event of an epidemic or event. We drafted a comprehensive overhaul of the laws for communicable disease containment, focusing on quarantine and isolation.

Through hard work and a committed group of advocates, our proposed legislation unanimously passed both houses of our General Assembly intact. Following this passage, the statutes were signed by our governor and are now state law. The process took about a year and a half. I have identified a number of "keys to success" in the creation or revision of public health laws.

It is imperative to develop a core of informed and committed advocates. These individuals should be drawn from a variety of groups including public health, the legal community and homeland security planners. It is essential that any group undertaking the task of updating communicable disease laws understands the full scope of the task: detection, response, enforcement and oversight. The key stakeholders impacted by any change in law must be identified and often include members of the legislature, the judiciary, law enforcement and commercial interests. Especially important is the early understanding of major "hot button" issues. In our experience these issues included the triggers for imposition of mandatory quarantine, the use of private facilities and the role of the media. The core advocacy group can be used to discuss and resolve hot-button issues. This strategy builds consensus in phases and leads to a momentum that results in passage of desired laws. A neutral facilitator, who is seen being independent, is a key to success. This was one of my roles in the process. In any undertaking of this magnitude, it is important to expect the unexpected and accept that everything cannot be accomplished at once.

\section{Steve Shakman}

Like most states, Minnesota was prompted by the tragic events of September $11^{\text {th }}$ and the subsequent anthrax mailings to reexamine emergency management and public health laws, especially those authorizing isolation and quarantine. Our revised quaran- tine statutes were heavily influenced by the Model State Emergency Health Powers Act's emphasis on aiding individuals exposed to or infected with a communicable disease. We are currently working with local health boards, as well as community groups, to develop the capacity to address daily needs of persons if an outbreak were to require large-scale home quarantine or sheltering in place.

As an outreach effort spurred by the SARS experience in Ontario, the state health department and the district court in Ramsey County (St. Paul) sponsored a class on federal and state quarantine law for the state's legal community. It included a session on basics of infection control for court personnel and counsel. A recruitment component of the class was intended to develop a panel of defense counsel ready to represent persons subject to quarantine orders. Response from the state's bar was very encouraging. While the health department emphasizes training and public education, it also recognizes that there is a need for a credible system of sanction with meaningful due process for those who fail to cooperate with community public health measures.

Additionally, cross-education among public health and partners in both the public and private sectors is essential preparation for possible quarantine or isolation. Minnesota has had productive experiences in collaboration among public health and a number of diverse constituents including the news media, the legal community, law enforcement, emergency managers, voluntary organizations, and health care providers. Our commitment to collaborative undertakings has resulted in several ongoing projects to increase Minnesota's preparedness. For example, our ECHO initiative is developing TV programs in six languages for airing in the fall to explain health emergency efforts to persons whom we might not reach via English broadcasts. We are working with hospitals on establishment of a "cache" to provide emergency medications in the hours before the arrival of the national stockpile. Other projects underway are training videos for law enforcement on quarantine law and personal protective measures, and a database for tracking each person's quarantine to both enhance our ability to provide treatment and services and to ensure that quarantine orders are being observed. While we cannot yet discern the endpoint of this endeavor, we can see progress being achieved.

\section{Howard Markel}

My personal interest in isolation and quarantine issues came from dealing with AIDS patients during 
the 1980 s and the ongoing debate at the time about what was considered prudent public health measures. The issue of diseases and community response to them has existed throughout recorded history. For example, there is extensive biblical mention of disease and disease control measures in the Book of Leviticus. The seventh century marked the first time disease spread over long distances. The word "quarantine" originates from fourteenth century Italy. In historical context, this restrictive, forty-day public health control measure known as quarantine, was largely based on the Hippocratic theory of transmission.

Since its origin in the Middle Ages, there has been a continual refinement or quarantine and the way this control measure is viewed by societies. The recent SARS epidemic in Asia and North America drew needed attention to the long-neglected use of quarantine as a public health tool and highlighted several evolutionary changes brought on by technology and increased knowledge of disease. The prevailing concern behind the societal use of nineteenth century quarantine measures was to get the sick away from "us." Public health officers in the United States had broad ex parte powers and this was evidenced in New York City's 1892 response to cholera.

Throughout the twentieth century, quarantine increasingly faded from use as a public health measure for disease control and before SARS, its mere discussion by public health officials elicited suspicion.
SARS, while tragic, provided the opportunity to reexamine both the use of quarantine and the laws authorizing its implementation. Recognizing the technological improvements in disease identification and heightened surveillance capabilities, many jurisdictions modified antiquated quarantine laws to reflect modern scientific theory and legal notions of due process and equal protection.

Perhaps the greatest outcome of the SARS epidemic is the development of innovative approaches to quarantine that serve a narrow and necessary public health goal without being violative of individual liberties or capricious in application. Each nation can implement quarantine laws that best reflect its unique cultural distinctions-what may work in Asia or Canada may not work in the United States. Singapore authorizes quarantine and isolation measures that greatly restrict suspected disease carriers' freedom, but this authority comports with their common cultural experience. Among the most notable developments concerning quarantine that emerged from SARS was the use of "snow days." This innocuous name can be utilized as a political tool for getting persons to slow their daily interactions. Another method is the introduction of "voluntary quarantines" for a specified length of time. While this name may be a misnomer and could more accurately be called "verbal mandatory" quarantine, it proved highly effective in Toronto by encouraging widespread compliance. 